\title{
ХІРУРГІЯ
}

\author{
Д.О. Кулікова
}

ДУ «Інститут загальної та невідкладної хірургї̈ ім. В.Т. Зайцева НАМНУ», м. Харків

\section{ВИКОРИСТАННЯ АЛГОРИТМУ УЛЬТРАЗВУКОВОЇ ДІАГНОСТИКИ ДЛЯ ПРОГНОЗУВАННЯ ПОДАЛЬШОГО РОЗВИТКУ ВІДКРИТОЇ АРТЕРІАЛЬНОЇ ПРОТОКИ В ДІТЕЙ}

\begin{abstract}
Проведено порівняльний аналіз даних обстеження й лікування 158 дітей, які народилися 3 нормальним терміном гестації. До основної групи ввійшли 77 дітей (ізольована відкрита артеріальна протока мала місце у 42 дітей, поєднана із вторинним дефектом міжпередсердної перегородки - у 35). Групу порівняння становила 81 дитина (із ізольованою відкритою артеріальною протокою - 46 дітей та 3 відкритою артеріальною протокою в комбінації з вторинним дефектом міжпередсердної перегородки - 35). Доведено, що використання запропонованих діагностичного алгоритму та ультразвукових методик надає можливість визначати гемодинамічну значущість відкритої артеріальної протоки та передбачати іії самозакриття в разі ізольованої вади та зневажання невеликим вторинним дефектом міжпередсердної перегородки за його комбінації з гемодинамічно значущою відкритою артеріальною протокою, що дозволило уникнути зайвих оперативних втручань, зокрема з використанням штучного кровообігу.

Ключові слова: відкрита артеріальна протока, вторинний дефект міжпередсердної перегородки, ультразвукова діагностика.
\end{abstract}

\section{Вступ}

Дотепер залишається актуальною проблема вроджених вад серця в дітей. Вагома частина їх залишаються безсимптомними і недіагностованими в неонатальному періоді та проявляються лише через тижні або роки після народження $[1,2]$. Однією 3 найпоширеніших уроджених вад серця є відкрита артеріальна протока (ВАП), яка характеризується сполученням між аортою і легеневою артерією [3]. Прояви ВАП можуть варіювати залежно від ii розміру, взаємозв'язку системного й легеневого судинного опору. Клінічні симптоми можуть сягати проявів від застійної серцевої недостатності і високої легеневої гіпертензії, що потребують термінових дій, до повної відсут- ності будь-яких ознак, окрім наявності скидання [4].

Відкрита артеріальна протока може зустрічатись як в ізольованому вигляді, так і в поєднанні з іншими вадами серця й судин, а іiі функціонування може як обтяжувати перебіг супутніх вад, так і компенсувати виникаючі в результаті їхнього існування порушення [5].

Питання діагностики й лікування глибоко недоношених дітей 3 малою масою широко висвітлено в літературі [6]. При цьому показання до визначення значущості ВАП, а саме: іiі гемодинамічної значущості (ГЗ), критеріїв ультразвукової (УЗ) діагностики як основного методу, у дітей, які народились із нормальним терміном гестації, дотепер залишаються су-

(С) Д.О. Кулікова, 2019 
перечливими [7]. Існують критерії протипоказань до оперативного лікування дітей із ВАП, які базуються на даних ендоваскулярного дослідження. Щодо критеріїв необхідності лікування, то зустрічаються посилання тільки на $\Gamma 3$, чіткого визначення якої також немає $[8,9]$.

Таким чином, відсутність єдиної концепції у визначенні критеріїв ГЗ ВАП, алгоритму прогнозування перебігу захворювання, а також ведення доношених дітей із ВАП роблять цю проблему актуальною.

Мета даного дослідження - визначення ефективності розробленого алгоритму діагностичних і прогностичних аспектів ультразвукових ознак гемодинамічної значущості відкритої артеріальної протоки в дітей.

\section{Матеріал і методи}

Дослідження виконано на базі кардіохірургічного відділення ДУ «Інститут загальної та невідкладної хірургії ім. В.Т. Зайцева НАМН України». Проведено порівняльний аналіз двох груп загальною кількістю 158 пацієнтів, які народились із нормальним терміном гестації, що проходили обстеження й лікування в кардіохірургічному відділенні в період 2017-2019 років. До основної групи ввійшли 77 дітей, із них ізольована ВАП мала місце у 42 (54,5 \%) осіб та ВАП у поєднанні із вторинним дефектом міжпередсердної перегородки (ДМПП) у $35(45,5$ \%). До групи порівняння було віднесено 81 дитину, із них 46 (56,8 \%) осіб були 3 ізольованою ВАП та 35 (43,2 \%) - із ВАП у комбінації із вторинним ДМПП.

Пацієнти основної групи проходили УЗобстеження на основі розробленого алгоритму діагностики та прогнозування подальшого розвитку ВАП, а також у разі необхідності алгоритму диференційної діагностики гемодинамічного переважання ВАП у випадках комбінування із вторинним ДМПП. Пацієнти групи порівняння проходили обстеження й лікування до 2018 року без використання запропонованих методик.

Алгоритм діагностики і прогнозування подальшого розвитку ВАП складався $з$ декількох етапів. На першому етапі встановлюють діагноз ВАП (наявність візуалізації ВАП у В-режимі та/або кольоровому допплерівському картуванні з наявністю ліво-правого скидання в одній із позицій: парастернальній позиції по короткій осі, «високій» парастернальній та супрастернальній). На другому етапі роз- раховували ступінь ії ГЗ, тобто ВАП може бути гемодинамічно незначущою (ГНЗ), гемодинамічно помірно-значущою та гемодинамічно значущою. За ступенем ГЗ насамперед визначають необхідність і терміни оперативного втручання або тактику динамічного спостереження за паціснтами. За необхідності на третьому етапі застосовують додаткові методи визначення ГЗ, а саме: розрахунок співвідношення площі скидання по ВАП до площі легеневої артерії та вимірювання швидкості й відповідності систоло-діастолічної різниці потоку скидання по ВАП при вимірюванні постійно-хвильовим допплером із відповідними показниками: незначущі - більше $51 \%$, помірно значущі - 50-31\% і значущі - менш ніж $30 \%$ відповідно.

Алгоритм диференційної діагностики гемодинамічного переважання ВАП у випадках комбінування цієї вади з іншими вторинними дефектами передбачає врахування не лише даних УЗ-дослідження, а й результатів аускультації, електрокардіографії та рентгенографії. Однак важливість і діагностична цінність УЗ-дослідження займають ключову позицію в алгоритмі.

\section{Результати та їх обговорення}

Завдяки використанню розроблених алгоритмів УЗ-діагностики у практичній діяльності лікарів можна забезпечити системність i зручність їхньої роботи, скоротити час обстеження пацієнта та час приймання прогностичного рішення. Проведено порівняльний аналіз пацієнтів двох груп - основної і групи порівняння - із використанням таких параметрів:

- кількість інвазивних методик для визначення тактики ведення пацієнта;

- відсоток помилок при УЗ-діагностиці;

• кількість випадків ГНЗ ВАП під час закриття;

- відсоток випадків самозакриття ВАП за ізольованої вади;

- відсоток самозакриття вторинного ДМПП за комбінації з ВАП.

Під час упровадження розроблених алгоритмів у практику отримано такі результати (таблиия).

У групі дітей, обстеження яких проводилось відповідно до запропонованих алгоритмів, достовірно менше доводилось залучати до діагностичного процесу інвазивні методики, такі як ендоваскулярна діагностика та комп'ю- 
Критерії підрахунку переваги розробленої методики

\begin{tabular}{l|c|c|c|c}
\hline \multicolumn{1}{c|}{ Параметр порівняння } & \multicolumn{2}{|c|}{ Основна група $(\mathrm{n}=77)$} & \multicolumn{2}{|c}{ Група порівняння $(\mathrm{n}=81)$} \\
\cline { 2 - 5 } & абс. & $\%(\mathrm{P} \pm \mathrm{m})$ & абс. & $\%(\mathrm{P} \pm \mathrm{m})$ \\
\hline Інвазивні методики & 3 & $3,9 \pm 2,2$ & 11 & $13,6 \pm 3,8$ \\
Помилки УЗ-діагностики & 7 & $9,1 \pm 3,3$ & 19 & $23,5 \pm 3,8$ \\
Кількість ГНЗ ВАП під час закриття & 4 & $5,2 \pm 2,5$ & 13 & $16,0 \pm 4,1$ \\
Самозакриття ВАП $(\mathrm{n}=24)$ & 22 & $91,7 \pm 5,8$ & - & - \\
Самозакриття вторинного ДМПП $(\mathrm{n}=9)$ & 8 & $88,9 \pm 11,1$ & - & - \\
\hline
\end{tabular}

терна томографія в ангіорежимі з використанням контрастної речовини, а саме: у $(3,90 \pm 2,25) \%$ дітей основної групи відносно показника дітей групи порівняння, де цей відсоток дорівнював $(13,6 \pm 3,8)$.

Серед помилок УЗ-діагностики в даному дослідженні вважалися насамперед перебільшення ГЗ ВАП. При використанні розроблених алгоритмів відсоток таких помилок у дітей основної групи зменшився до $(9,1 \pm 3,3)$ у порівнянні $3(23,5 \pm 3,8)$ у групі порівняння.

При визначенні ступеня ГЗ були враховані такі випадки ВАП, коли ГНЗ ВАП потребували оперативного втручання через наявність у дітей частих захворювань легень тяжкого ступеня або хронічної інфекції. У основній групі таких випадків було $(5,2 \pm 2,5) \%$, а в групі порівняння - $(16,0 \pm 4,1) \%$.

Крім того, за використання алгоритмів спостерігались випадки самозакриття ВАП та самозакриття вторинного ДМПП-у $(91,7 \pm 5,8)$ та $(88,9 \pm 11,1) \%$ відповідно, тоді як у групі порівняння таких ситуацій не виявлено.

\section{Висновки}

Використання розроблених алгоритмів дозволяє знизити необхідність використання інвазивних методик діагностики без утрати діагностичного рівня на 72,7 \%. Кількість діагностичних помилок при використанні ультразвукових ознак за розробленою методикою зменшено на 63,2 \% за інтраопераційними даними, що дозволило майже уникнути закриття гемодинамічно незначущих відкритих артеріальних проток. При використанні прогностичної методики й алгоритму ведення пацієнтів стало можливим передбачувати самозакриття протоки в разі ізольованої вади та зневажання вторинним дефектом міжпередсердної перегородки за його комбінації з гемодинамічно значущими відкритими артеріальними протоками, що дозволило уникнути зайвих оперативних втручань, зокрема із використанням штучного кровообігу. Даний факт підтверджує важливість запропонованих алгоритмів у практиці охорони здоров'я.

Перспективність дослідження

Необхідно відмітити, що в жодному разі неможливо виключати індивідуальний підхід до кожного пацієнта. Ця методика може бути використана, але має працювати в комплексі 3 оцінюванням інших важливих критеріїв, у тому числі й анамнестичних, соціальних та клінічних.

\section{Список літератури}

1. Krasuski R. A. Congenital heart disease epidemiology in the United States: blindly feeling for the charging elephant / R. A. Krasuski, T. M. Bashore // Circulation. - 2016. - Vol. 134 (2). - P. 110-113.

2. Who should be targeted for the prevention of birth defects? A latent class analysis based on a large, population-based, cross-sectional study in Shaanxi Province, Western China / Z. Zhu, Y. Cheng, W. Yang [et al.] // PLoS One. - 2016. - Vol. 16, № 11 (5). - e0155587.

3. Калашникова Е. А. Открытый артериальный проток: особенности ранней неонатальной, постнатальной диагностики, клинической манифестации, лечение и прогноз [Электронный ресурс] / Е. А. Калашникова, Н. А. Никитина // Здоровье ребенка. - 2017. - Т. 12, № 2. - С.171-176.

4. 2018 AHA/ACC Guideline for the management of adults with congenital heart disease: a report of the American college of cardiology / American heart association task force on clinical practice guidelines / K. K. Stout, C. J. Daniels, J. A. Aboulhosn [et al.] // AHA J. Circulation. - 2019. - Vol. 139, № 14. P. 698-800.

5. Чепурных E. E. Врожденные пороки сердца / Е. Е. Чепурных, Е. Г. Григорьев // Сибирский медицинский журнал. - 2014. - № 3. - С. 121-127. 
6. Which criteria are more valuable in defining hemodynamic significance of patent ductus arteriosus in premature infants? Respiratory or Echocardiographic? / Irfan Oguz Sahin, Canan Yolcu, Aysegul Elbir Sahin [et al.] // Med. Bull. Haseki. - 2017. - Vol. 55. - P. 32-36.

7. Arlettaz R. Echocardiographic evaluation of patent ductus arteriosus in preterm infants / R. Arlettaz // Frontiers in Pediatrics. - 2017. - Vol. 5, № 147. - P. 1-9.

8. Evans $N$. Compliance with this Guideline is recommended: women and babies: management of patent ductus arteriosus in preterm infants / Primary author Nick Evans. - Sydney Local Health District, 2016. -19 p.

9. Effectiveness and safety of treatments used for the management of patent ductus arteriosus (PDA) in preterm infants: a protocol for a systematic review and network meta-analysis / S. Mitra, I. D. Florez, M. E. Tamayo [et al.] // BMJ Open. - 2016. - Vol. 6, № 7. - P. e011271.

\section{References}

1. Krasuski R.A., Bashore T.M. (2016). Congenital heart disease epidemiology in the United States: blindly feeling for the charging elephant. Circulation, vol. 134 (2), pp. 110-113.

2. Zhu Z., Cheng Y., Yang W., Zhu Z., Cheng Y., Yang W. et al. (2016). Who should be targeted for the prevention of birth defects? A latent class analysis based on a large, population-based, cross-sectional study in Shaanxi Province, Western China. PLoS One, vol. 16, № 11 (5), e0155587.

3. Kalashnikova Ye.A., Nikitina N.A. (2017). Otkrytyi arterialnyi protok: osobennosti rannei neonatalnoi, postnatalnoi diahnostiki, klinicheskoi manifestatsii, lecheniie i prohnoz [Open ductus arteriosus: features of early neonatal, postnatal diagnosis, clinical manifestation, treatment and prognosis]. Zdorovie rebenkaChild Health, vol. 12, № 2, pp. 171-176 [in Russian].

4. Stout K.K., Daniels C.J., Aboulhosn J.A., Bozkurt B., Broberg C.S., Colman J.M. et al. (2019). 2018 AHA/ACC Guideline for the management of adults with congenital heart disease: a report of the American college of cardiology / American heart association task force on clinical practice guidelines. AHA J. Circulation, vol. 139, № 14, pp. 698-800.

5. Chepurnykh Ye.Ye., Grigoriev Ye.H. (2014). Vrozhdennyie poroki serdtsa [Congenital heart defects]. Sibirskii meditsinskii zhurnal - Siberian Medical Journal, № 3, pp. 121-127 [in Russian].

6. Irfan Oguz Sahin, Canan Yolcu, Aysegul Elbir Sahin, Mustafa Kara, Yasar Demirelli, Hasim Olgun, Naci Ceviz (2017). Which criteria are more valuable in defining hemodynamic significance of patent ductus arteriosus in premature infants? Respiratory or Echocardiographic? Med. Bull. Haseki, vol. 55, pp. 32-36.

7. Arlettaz R. (2017). Echocardiographic evaluation of patent ductus arteriosus in preterm infants. Frontiers in Pediatrics, vol. 5, № 147, pp. 1-9.

8. Evans N. (Primary author). (2016). Compliance with this Guideline is recommended: women and babies: management of patent ductus arteriosus in preterm infants. Sydney Local Health District, $19 \mathrm{p}$.

9. Mitra S., Florez I.D., Tamayo M.E., Aune D., Mbuagbaw L., Veroniki A.A., Thabane L. (2016). Effectiveness and safety of treatments used for the management of patent ductus arteriosus (PDA) in preterm infants: a protocol for a systematic review and network meta-analysis. BMJ Open, vol. 6, № 7, pp. e011271.

\section{Д.А. Куликова \\ ИСПОЛЬЗОВАНИЕ АЛГОРИТМА УЛЬТРАЗВУКОВОЙ ДИАГНОСТИКИ ДЛЯ ПРОГНОЗИРОВАНИЯ ДАЛЬНЕЙШЕГО РАЗВИТИЯ ОТКРЫТОГО АРТЕРИАЛЬНОГО ПРОТОКА У ДЕТЕЙ}

Проведен сравнительный анализ данных обследования и лечения 158 детей, родившихся с нормальным сроком гестации. В основную группу вошли 77 детей (изолированный открытый артериальный проток имел место у 42 детей, сочетанный с вторичным дефектом межпредсердной перегородки - у 35). Группу сравнения составил 81 ребенок (с изолированным открытым артериальным протоком - 46 детей и с открытым артериальным протоком в сочетании с вторичным дефектом межпредсердной перегородки - 35). Доказано, что использование предложенных диагностического алгоритма и ультразвуковых методик позволяет определять гемодинамическую значимость открытого артериального протока и предусматривать его самозакрытие при изолированном пороке и пренебречь небольшим вторичным дефектом межпредсердной перегородки при его комбинации с 
гемодинамически значимым открытым артериальным протоком, что позволило избежать оперативных вмешательств, которые не нужно делать, в частности с использованием искусственного кровообращения.

Ключевые слова: открытый артериальный проток, вторичный дефект межпредсердной перегородки, ультразвуковая диагностика.

\section{D.O. Kulikova}

\section{USE OF THE ULTRASOUND DIAGNOSTIC ALGORITHM FOR FORECASTING FURTHER} DEVELOPMENT OF PATENT DUCTUS ARTERIOSUS IN CHILDREN

A comparative analysis of the data of examination and treatment of 158 children, who were born with a normal gestational age, was carried out. The main group consisted of 77 children (isolated open ductus arteriosus occurred in 42 children, combined with a secondary atrial septal defect occurred in 35 children). The comparison group consisted of 81 children (46 children are with an isolated open ductus arteriosus and 35 children are with an open ductus arteriosus in combination with a secondary atrial septal defect). It is proved, that the use of the proposed diagnostic algorithm and ultrasonic techniques allows us to determine the hemodynamic significance of the patent ductus arteriosus and provide for its self-closure in case of isolated defect and neglect a small secondary defect of the atrial septum when combined with a hemodynamically significant patent ductus arteriosus, that gave an option of avoidance of unnecessary surgical interventions, including the use of cardiopulmonary bypass.

Keywords: patent ductus arteriosus, secondary atrial septal defect, ultrasound examination.

Надійшла 27.02.19

\section{Відомості про автора}

Кулікова Дар’я Олександрівна - лікар-педіатр відділення кардіохірургії ДУ «Інститут загальної та невідкладної хірургії ім. В.Т. Зайцева НАМН України», м. Харків.

Адреса: 61103, м. Харків, в’їзд Балакірєва, 1, ДУ «Інститут загальної та невідкладної хірургії ім. В.Т. Зайцева НАМН України».

Тел.: +38(063)628-73-45;+38(097)379-18-07.

E-mail: dariakulikova@gmail.com.

ORCID: https://orcid.org/0000-0002-3087-5874. 